\title{
Retraction Note: Environmental change of rainfall erosivity based on GIS system and architectural design of sponge city
}

\author{
Ya Guo ${ }^{1}$
}

Published online: 6 December 2021

(c) Saudi Society for Geosciences 2021

Retraction Note to: Arabian Journal of Geosciences (2021) 14: 1780 https://doi.org/10.1007/s12517-021-08095-y

The Editor-in-Chief and the Publisher have retracted this article because the content of this article is nonsensical. The peer review process was not carried out in accordance with the Publisher's peer review policy. The author has not responded to correspondence regarding this retraction.

The original article can be found online at https://doi.org/10.1007/ s12517-021-08095-y.

Ya Guo

guoya123guoya@163.com

1 Department of Architectural and Engineering,

Qinhuangdao College, Northeast Petroleum University,

Qinhuangdao 066004, Hebei, China 